\title{
Formation Mechanism and Prediction Method for the Permian Fused Breccia Tuff Reservoir, Wuxia Region, Junggar Basin
}

\author{
Duonian Xu ${ }^{\mathbb{D}},{ }^{1}$ Jianguo Pan, ${ }^{1}$ Shuxin Pan, ${ }^{1}$ Bin Gao, ${ }^{2}$ Lu Yin, ${ }^{1}$ Yongqiang Qu, \\ and Lei Zhang ${ }^{3}$ \\ ${ }^{1}$ Northwest Branch of Research Institute of Petroleum Exploration and Development, PetroChina, Lanzhou, 730020 Gansu, China \\ ${ }^{2}$ North China University of Science and Technology, Tangshan, Hebei 063210, China \\ ${ }^{3}$ Research Institute of Exploration and Development, Xinjiang Oilfield Company, PetroChina, Karamay, 834000 Xinjiang, China
}

Correspondence should be addressed to Duonian Xu; xu_dn@petrochina.com.cn

Received 7 February 2021; Accepted 10 June 2021; Published 23 June 2021

Academic Editor: Yi-Dong Cai

Copyright ( 2021 Duonian Xu et al. This is an open access article distributed under the Creative Commons Attribution License, which permits unrestricted use, distribution, and reproduction in any medium, provided the original work is properly cited.

\begin{abstract}
Fused breccia tuff occurs globally, but its formation mechanism is very controversial. Volcanic reservoirs have developed at the bottom of the Permian Fengcheng Formation in the Wuxia region of the Junggar Basin, and here, the lithology is fused breccia tuff. The reservoir porosity is mainly vesicles, but the development and relative filling of the vesicles vary spatially, resulting in strong reservoir heterogeneity. Through core and thin section observations and structural analysis, and combined with reconstructions of the paleosedimentary environment, we discussed in detail the formation mechanism of the fused breccia tuff reservoir. Our conclusions are as follows. In the high-temperature and high-pressure environment of the deep crust, intermediate acidic lava containing volatile components rapidly rose to the earth's surface along a fault. The volatile components in the lava foamed strongly and then exploded due to the sharp decline of pressure and temperature. A small part of the volcanic dust and pyroclastic material was erupted into the upper atmosphere. Most of the magma became magmatic pyroclast, vitric pyroclast, rock debris, dust, and other matter. This material was in a semimolten state and overflowed into a nearby lowlying lake. The extremely high-temperature pyroclastic flow quickly vaporized the water into high-pressure water vapor, which was squeezed into the pyroclastic flow and became mixed with other volatiles in the foam. On cooling, the pyroclastic material solidified into rock, and the vesicles were preserved. In a later period, due to strong tectonic movement, faults and fractures developed, surface water penetrated into the vesicles along the faults and fractures, and silica and other substances were deposited, filling the primary vesicles. To quantify the development and relative filling of vesicles, drilling parameters were used to establish different geologic models, and wave equation forward modeling was used to obtain a relationship between the development and filling of vesicles, and the seismic amplitude. The 3D seismic amplitude attributes were then extracted to predict the extent of the reservoir, yielding prediction results consistent with the drilling observations.
\end{abstract}

\section{Introduction}

Volcanic oil and gas reservoirs are being continuously discovered all over the world, attracting the attention of oil and gas exploration circles in China and abroad. However, volcanic reservoirs are complex, and their exploration and development remain a global challenge [1-3]. Volcanic reservoirs have developed at the bottom of the Permian Fengcheng Formation, in the Wuxia region at the northwest margin of the Junggar Basin, and have a fused breccia tuff lithology [4]. This particular fused breccia tuff is very different from tuff in ordinary meaning: specifically, it has no stratification but has strong fluidity and pseudofluidal structures, the vitric pyroclasts and magmatic pyroclasts are arranged in elongated orientations, the storage space is mainly vesicles with spatially variable levels of development and filling, and the heterogeneity of the reservoir is relatively strong, resulting in varying hydrocarbon enrichment between regions. Therefore, researching the formation mechanism of this set of fused breccia tuff reservoirs and quantitatively predicting 
its spatial extent are of great significance to oil and gas exploration and development.

Fused breccia tuff has been found globally, and scholars in China and abroad have extensively researched its formation mechanisms [5-18]. According to these studies, the following formation processes have been proposed by researchers. (1) Foaming magma: volatile-rich magma with higher viscosity rose to the surface, and due to the sudden drop of temperature and pressure, the gas foamed and escaped. Some magma remelted and became squeezed and fused under the action of gravity. (2) Volcanic sand rain: intermediate-acidic lava erupted into the air and was then deposited as volcanic sand (like hot raindrops) which then fused. (3) Volcanic ash flow: viscous, highly volatile, intermediate-acidic magma rose to the surface, and due to the sharp drop of pressure and temperature, a large amount of magma foamed, boiled, and exploded; the lava column containing vitric pyroclast, volcanic dust, crystal pyroclast, and other matters erupted from the crater, flowed into the low-lying areas near the crater, and then solidified into rock. (4) Lava flow: the formation is attributed to the solidification of foamy lava near the crater, which incorporated volcanic debris and lava lumps. Generally, fused breccia tuff represents a rock with a provenance lying between lava and pyroclastics, but since there is no existing volcanism example for reference, its formation mechanism is very controversial.

In terms of volcanic reservoir prediction, the methods that use seismic information to predict the volcanic reservoir mainly include seismic facies interpretation, seismic attribute extraction, reservoir inversion, and coherent slices [19-23]. These are generally qualitative methods, but with ongoing exploration, quantitative volcanic reservoir prediction technology must be developed [24-26]. As yet, no effective prediction method has been established to quantify the development and filling of vesicles in volcanic reservoirs in the research area.

This article takes the fused breccia tuff developed at the bottom of the Permian Fengcheng Formation in the Wuxia region of the Junggar Basin as an example. Starting from the rock mineral composition, paleomorphological background, and eruption environment, the study analyzes the formation mechanism of the fused breccia tuff reservoir and quantitatively predicts its extent, thus effectively guiding the oil and gas exploration in the research area.

\section{Geological Setting}

The Junggar Basin is the second largest inland basin in China and is located in northwest China (Figure 1(a)). The basin represents an irregular triangle, with the Tianshan Mountains to the south, the Altai Mountains to the northeast, and the Junggar Mountains to the northwest [27]. The terrain is high in the east and low in the west, with an average elevation of about $400 \mathrm{~m}$. The edges of the basin comprise foothills and oases, while the center is desert and grassland. The Wuxia region is located in the northeast part of the northwestern margin of Junggar Basin (Figure 1(b)). During the Middle and Late Carboniferous epochs, it was in the early basin formation stage; the Kazakhstan plate collided with the
Junggar terrane, the Western Junggar area entered a stage of rapid uplift and collision orogenesis, and the Junggar ocean basin was completely closed [28]. During the Permian Jiamuhe-Fengcheng Formation period, the basin was in the development stage of the foreland basin, and stress at the northwestern margin was characterized by transient relaxation within a weak compression background. During the Fengcheng Formation period, the basin then experienced tectonic uplift, subsidence, and reuplift and developed a thrust fault with a near NE-SW trend (Figure 1(c)); the associated sedimentary facies were mainly semideep to deep lakes. Under the influence of early tectonic movement and accompanied by volcanic activity, a set of pyroclastic rock reservoirs were formed. Eight wells in the research area encountered this set of fused breccia tuff (Figure 1(c)), which was later confirmed as a beneficial oil and gas accumulation zone by exploration. The strata developed from bottom to top in the Wuxia region include a Carboniferous stratum; Permian Jiamuhe Formation, Fengcheng Formation, Xiazijie Formation, and Urho Formation; and Triassic, Jurassic, and Cretaceous strata. The Permian Fengcheng Formation is widely distributed with a thickness between 300 and $500 \mathrm{~m}$; the lithology mainly includes argillaceous dolomite, tuff, tuffaceous mudstone, mudstone, and siltstone, which are in unconformable contact with the upper and lower strata (Figure 1(d)).

\section{Samples and Methods}

3.1. Samples. The fused breccia tuff samples analyzed in this article came from the Permian Fengcheng Formation in the Wuxia region at the northwest margin of the Junggar Basin. In the Wuxia region, 8 wells encountered the Permian Fengcheng Formation volcanic rocks. The well test results show that there is oil in this formation. Some $65.05 \mathrm{~m}$ of drilling core has been observed and described; 21 rock slices and 13 cast slices were collected from 5 wells; $\mathrm{Fe}^{2+}$ and $\mathrm{Fe}^{3+}$ were analyzed in 9 samples.

3.2. 3D Seismic Data. 3D seismic data were used to predict the spatial extent of the reservoir. Here, we use highdensity 3D data collected and processed in 2013, covering $300 \mathrm{~km}^{2}$, a number of coverage times of 1260 , a bin of 12.5 $\mathrm{m} \times 12.5 \mathrm{~m}$, and a target stratum frequency of about 30 $\mathrm{Hz}$. The seismic data had high signal-to-noise ratio and good amplitude preservation, thus meeting the requirements of reservoir prediction.

3.3. Method. The type, composition, and structure of the volcanic rock in the research area were determined using core observations, rock slice identification, and petrological analysis technology. Casting thin section analysis technology was adopted to obtain the microscopic characteristics of the reservoir porosity and to determine the tectonic background and sedimentary environment of the volcanic rock development, with the aid of geochemical analysis. Using the data, the formation mechanism of the volcanic reservoir was analyzed. Wave equation forward modeling technology was then used to clarify the seismic response characteristics of volcanic reservoirs and to establish the relationship between reservoir 


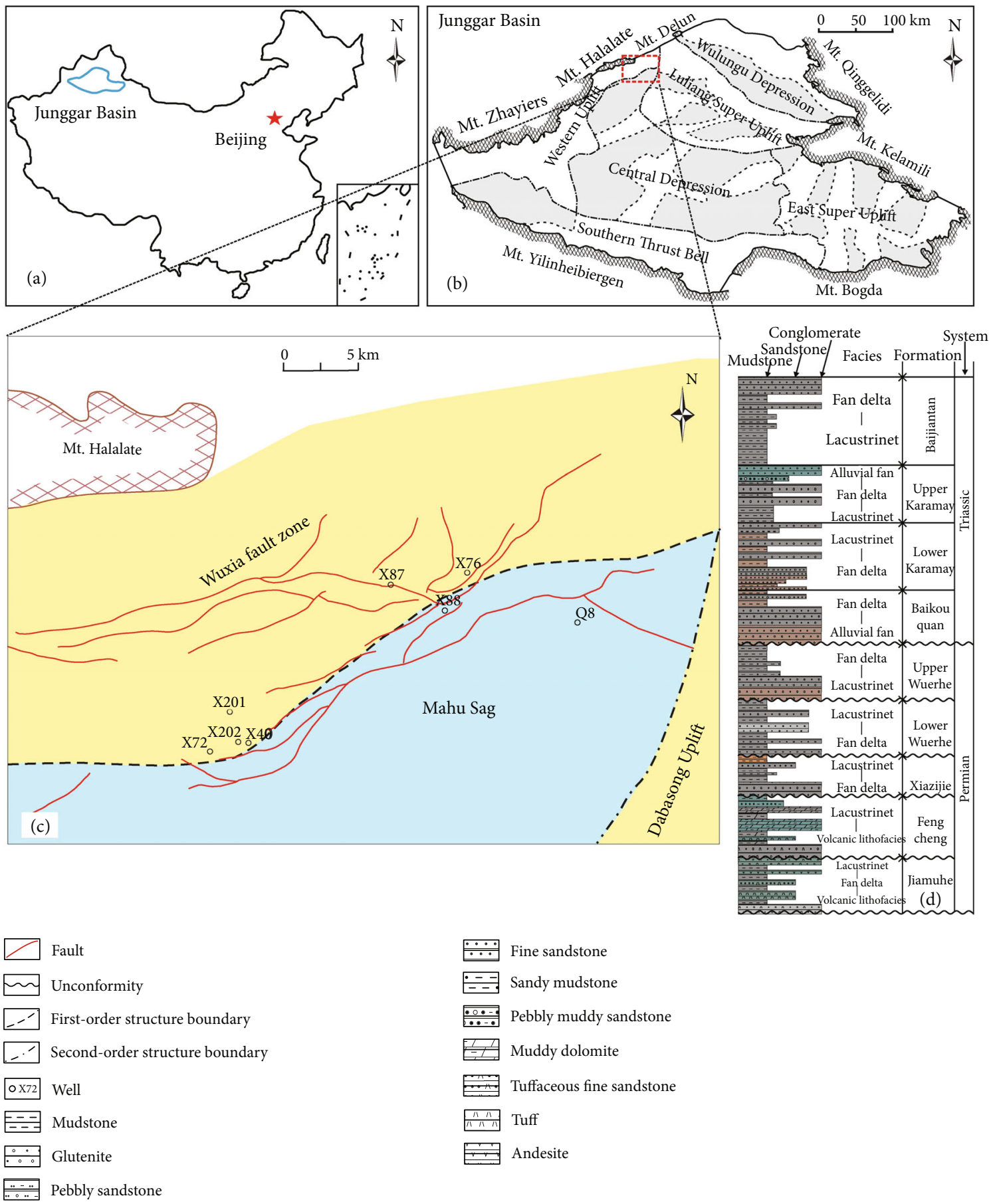

FIgure 1: (a) Geographical location of Junggar Basin in China. (b) Tectonic units of the Junggar Basin. (c) Geographical location of Wuxia region. (d) Lithological column.

quality and seismic attributes. Finally, 3D seismic data were used to predict the spatial distribution of the reservoir.

\section{Results}

The lithology of the volcanic rocks at the bottom of the Permian Fengcheng Formation mainly includes dark gray tuff, vesicular fused breccia tuff, and rhyolitic fused breccia tuff. The lithology of the Permian Fengcheng Formation in
Well X72 is vesicular fused breccia tuff; unfilled vesicles have developed with varying sizes and irregular shapes (Figure 2(a)). The lithology of Well X201 is rhyolitic fused breccia tuff; vesicles have developed and are partially filled; lentoid and long-strip flame bodies composed of magmatic pyroclast of varying sizes can be seen on the surface of the core; the flame bodies are breccia-like with a length of 20 $\mathrm{mm} \sim 40 \mathrm{~mm}$, directionally arranged and dark brown in color (Figure 2(b)). Based on thin section analysis, the rock 


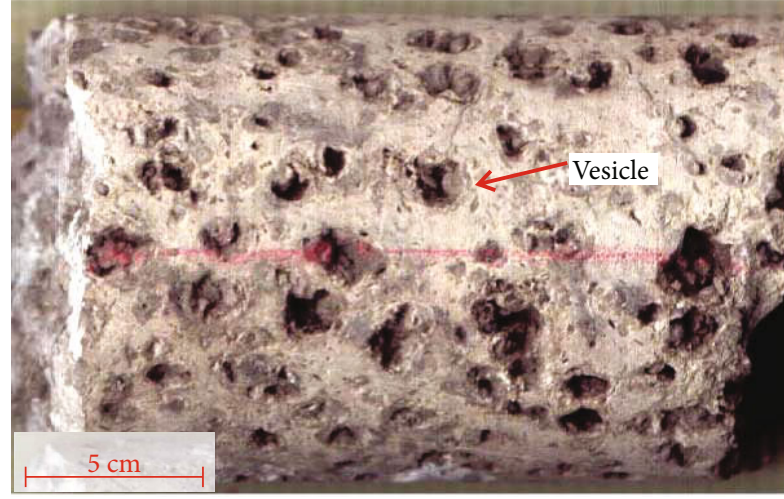

(a)

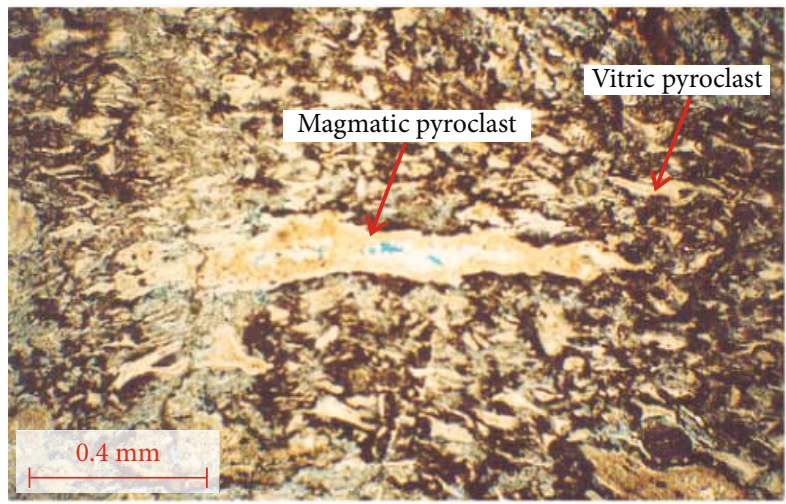

(c)

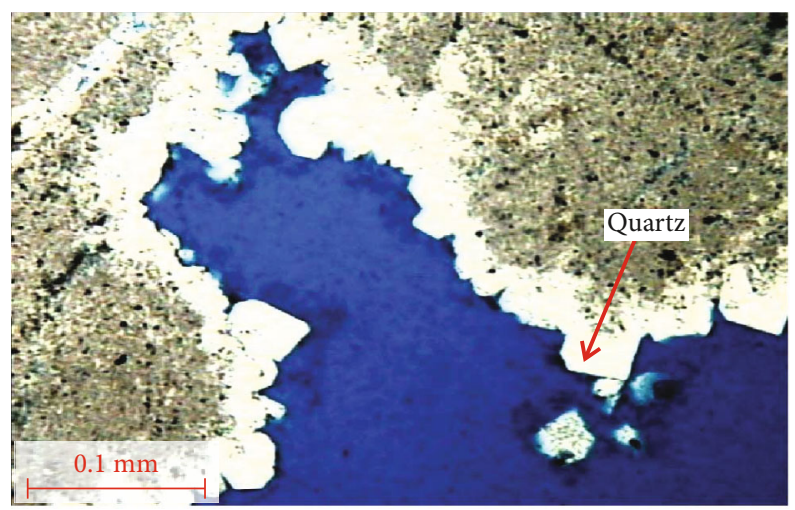

(e)

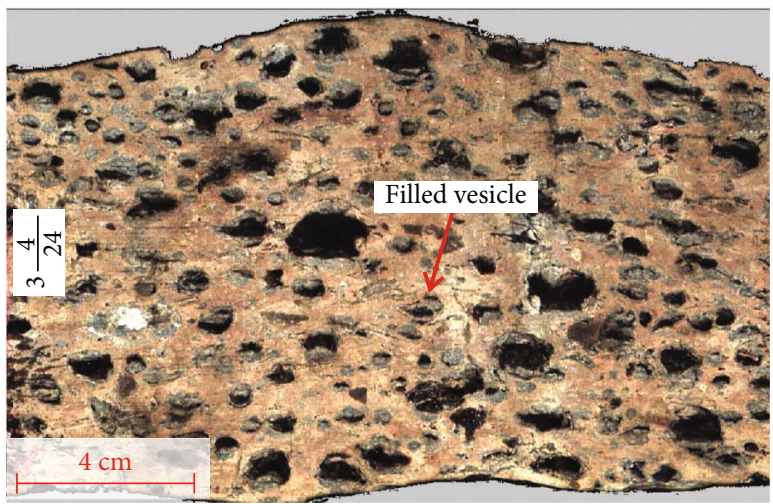

(b)

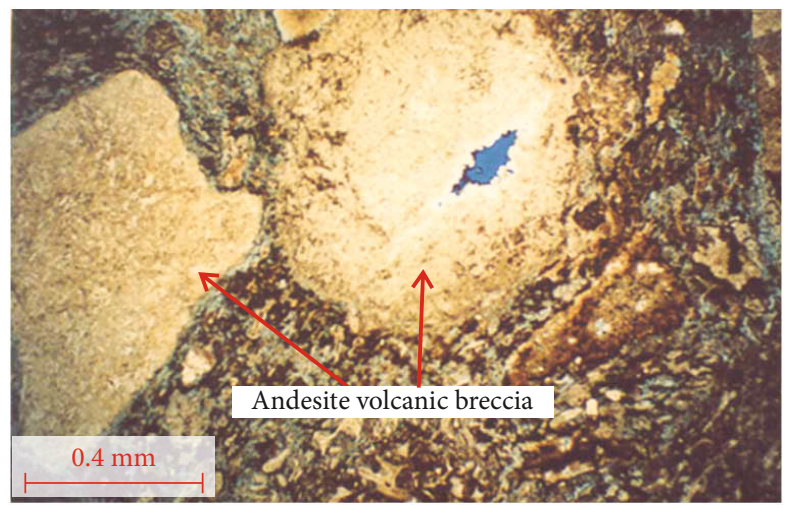

(d)

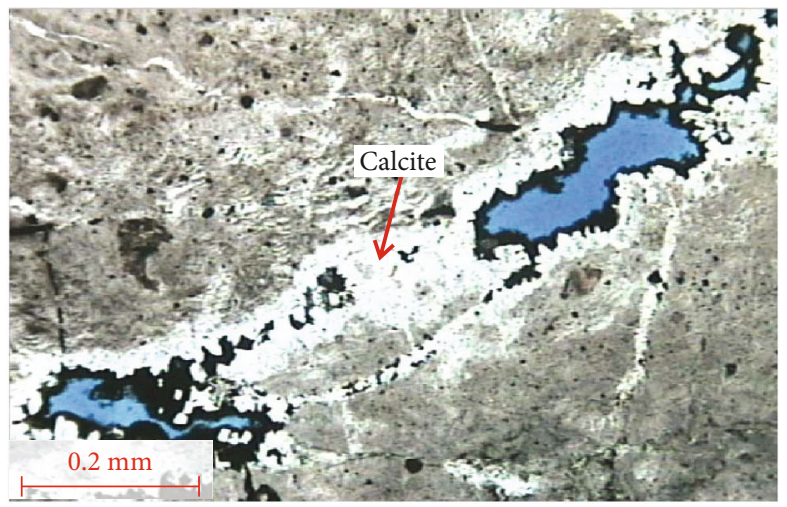

(f)

Figure 2: (a) Well X72, $4814 \mathrm{~m}$, rhyolitic fused breccia tuff with stoma development, $\times 20$, lithology photo. (b) Well X201, $4932.56 \mathrm{~m}$, the rock is mainly composed of volcanic breccia, vitric pyroclast, and tuffaceous matters, the volcanic breccia is composed of felsite and tuff, and the stomas are partially filled, $\times 20$, lithology photo. The rock around the vesicles displays fluorescence. (c) Well X202, $4824.11 \mathrm{~m}$, felsite rock debris, magmatic pyroclasts and vitric pyroclasts can be seen, $\times 40$, casting thin section. (d) Well X202, 4824 m, vitric pyroclast tuffaceous structure, andesite volcanic breccia can be seen, $\times 40$, casting thin section. (e) Well X72, $4808.62 \mathrm{~m}$, quartz particles can be seen at the edges of vesicles, $\times 40$, casting thin section. (f) Well X201, $4933.21 \mathrm{~m}$, vesicles are filled with quartz or calcite, $\times 25$, casting thin section.

was formed by melting of felsite rock debris, tuff breccia, plastic magmatic pyroclast, volcanic ash balls, plastic vitric pyroclast, and volcanic ash (Figure $2(\mathrm{c})$ ). The particle size of most felsite rock debris exceeds $2 \mathrm{~mm}$ and is brecciated. The vitric pyroclast was affected by fluid effects in the later stage, and devitrification was intensive after the temperature and pressure change; the pyroclast turned into a cryptocrystalline felsic mineral aggregate, and the long axis of the vitric pyroclast is aligned with the long axis of the magmatic pyroclast. The rock debris mainly comes from the surrounding rock of the volcanic conduit and the consolidated lava in the volcanic conduit, such as the andesite volcanic breccia in Well X202 (Figure 2(d)). In the vesicles of Well X72, crystalline granular quartz developed along the inner wall of the vesicles (Figure 2(e)), and the connectivity between the vesicles is poor. The fillings in the vesicles are mainly 
composed of quartz, calcite, and chlorite (Figure 2(f)), which belong to clastic minerals, indicating that they were filled in the later period.

The lithological characteristics of the volcanic rocks drilled in various wells in Wuxia region are basically the same, but the development and proportional filling of the vesicles are different. According to the core data, the vesicles developed in the core from Well X72 are mostly unfilled, and the reservoir physical properties are good. Well X76 has stoma development, but the vesicles are partially filled with chlorite. There are few vesicles in Well X88, Well Q8 also encountered this set of reservoirs, but the vesicles were completely filled and the reservoir physical properties deteriorated. It can be concluded from the above analysis that the development and filling of vesicles directly determine the quality of this set of volcanic reservoirs; therefore, it is crucial to research the formation mechanism and prediction method for this set of fused breccia tuff reservoirs.

\section{Discussion}

5.1. Formation Mechanism of the Fused Breccia Tuff Reservoir. The characteristics of the reservoir show that the storage space of this set of fused breccia tuff is mainly vesicles, but the development and filling of the vesicles vary spatially. The formation process of the vesicles is inseparable from the formation process of the fused breccia tuff. Therefore, research on the formation mechanism of the fused breccia tuff reservoir is directly relevant to the formation and filling mechanisms of the vesicles.

5.1.1. Formation Mechanism of Vesicles. The formation mechanism of vesicles in the fused breccia tuff of the Permian Fengcheng Formation in the Wuxia region has been extensively researched, but a consensus has yet been reached. Zhu believed that this set of pyroclastic rocks contains a large number of well-rounded volcanic spheroids; the vesicles and fractures are the main storage space of this set of reservoirs, and the formation mechanism of the spheroids remains unknown [29]. Xiao et al. believed that the formation of various vesicles in this set of reservoirs is closely related to the extent of solidification and fusion strength of pyroclastic materials; stronger fusion and higher content of magmatic pyroclast will promote greater volume and connectivity degree of the vesicles [30]. Wu et al. believed that euritic lumps enabled the main enrichment of vesicles, and the formation mechanism included pyroclastic materials with a lesser volatiles component accumulating near the crater; subsequently, the increased water pressure decreased the melting point of this set of pyroclastic rocks, and they were partially remelted [31]. Zhu et al. believed that this set of fused breccia tuff was formed by a high-temperature and high-speed volcanic ash flow accumulating near the crater; the gas did not dissipate immediately during the fusion process, but was sealed by a partially solidified hard shell early in the deposition period and formed bubbles; subsequently, the gas escaped and left bubble cavities during the condensation and devitrification processes [32]. Wang et al. studied the lithophysa structure in rhyolite and pointed out that the lithophysa had a well-rounded, multilayered concentric circle structure; these had varying sizes and degrees of crystallinity from the outside to the inside. Jiaqiang also pointed out that the development of lithophysa is related to the surrounding water accumulation: as the magma overflowed and rose above the water surface, the number of lithophysa decreased sharply and even disappeared [33]. Chen carried out detailed research on the rock composition and volcanic eruption paleogeographic environment of the Triassic marine rhyolitic fused breccia tuff in Longzhou County, Guangxi Province, concluding that the sedimentary environment at that time was an intertidal-supratidal environment, and that its lithology and structure were very similar to the fused breccia tuff of the Permian Fengcheng Formation in the Wuxia region [34].

From the perspective of the sedimentary paleoenvironment of the Permian Fengcheng Formation in the Wuxia region, dolomitic mudstone and dolomite developed in the Fengcheng Formation. These are deep, static-water deposits; therefore, You interpreted their paleoenvironment as a residual closed sea basin from the Permian period [35], while Yan et al. interpreted them as deep-lake semideep facies sediments [36], with normal sedimentary mudstone intercalated with dark gray volcanic rocks. The ratio $\mathrm{Fe}^{2+} / \mathrm{Fe}^{3+}$ in rocks is relatively sensitive to their formation environment and is thus a relatively effective indicator for determining the redox characteristics of the sedimentary environment [37]. The contents of $\mathrm{Fe}_{2} \mathrm{O}_{3}$ and $\mathrm{FeO}$ in the volcanic lava and pyroclastic rock samples in the research area were relatively low, indicating that the sedimentary environment is an underwater reduction environment.

Drilling shows a complete, fused tuff condensation unit developed in the third coring section of Well X201 (depth: 4,932-4,937.48 m), which can be divided into three vertical zones [32]. In these zones, the degree of fusion increased and then decreased, and the number of vesicles increased and then decreased, from bottom to top (Figure 3(a)). A weakly fused tuff was found at $4,936.5 \mathrm{~m}$, where cores were tight and vesicles did not develop (Figure 3(b)); this transited upwards to fused breccia tuff with a few vesicles at a burial depth of 4,936 m (Figure 3(c)); increasingly fused breccia tuff rich in vesicles was observed at $4,935.6 \mathrm{~m}$ (Figure 3(d)); at a burial depth of about $4,932 \mathrm{~m}$, the stoma content decreased again, and the lithology transited to weakly fused tuff (Figure 3(e)).

From the perspective of paleogeomorphology, the Wuxia region was relatively high and the water body was relatively shallow. Combining the tectonic activities, paleosedimentary environment, and rock composition during deposition of the Fengcheng Formation in the research area, this article proposes a "formation by explosion and water" provenance: the volcanic crater was located near the water surface and was affected by tectonic compression; intermediate-acidic magma rich in volatiles, originating in the deep crust under high temperature and high pressure, rose rapidly to the surface along the faults; the saturated volatile materials degassed from the lava and foamed strongly, before exploding due to the sharp decline of pressure and temperature. A small portion of the volcanic dust and pyroclastics was erupted into 


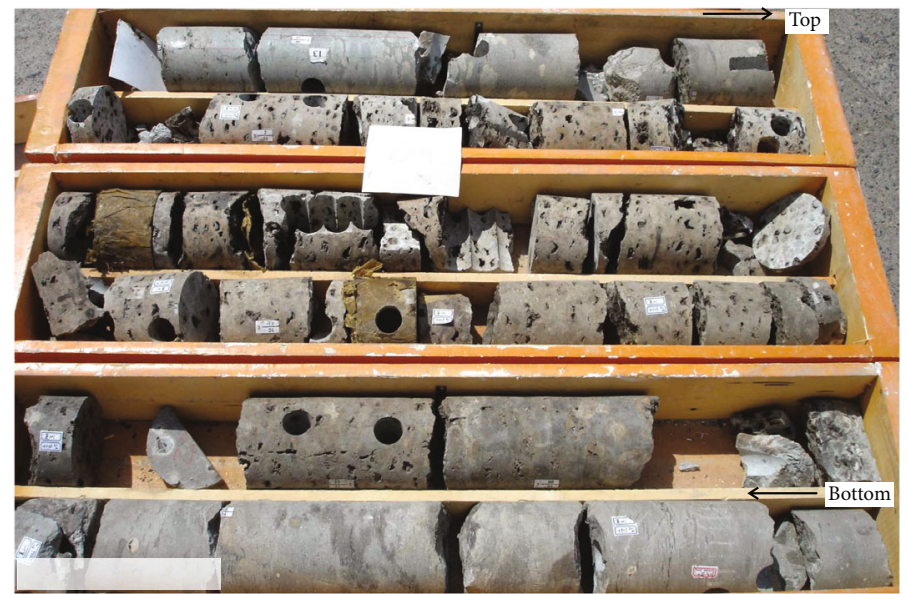

(a)

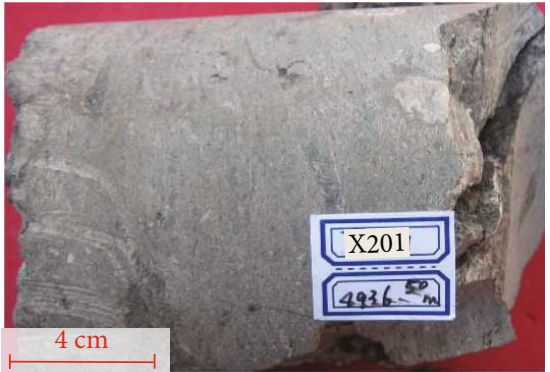

(b)

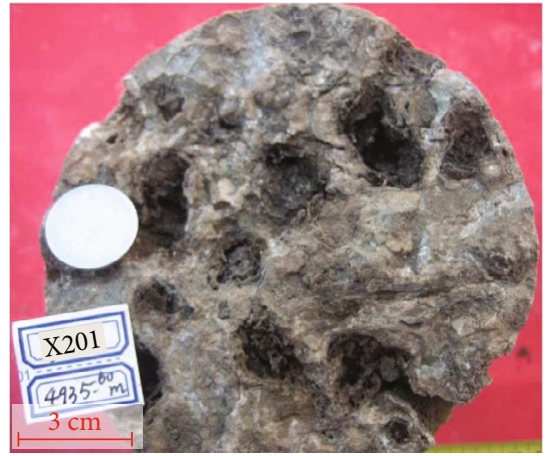

(d)

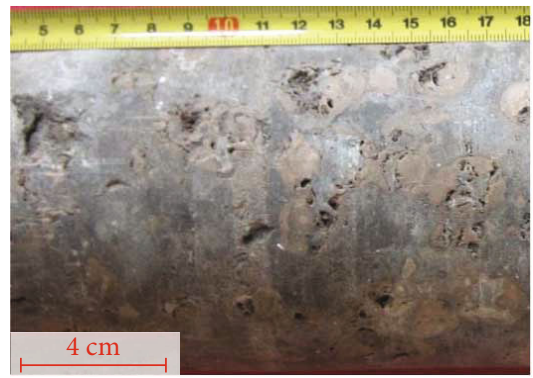

(c)

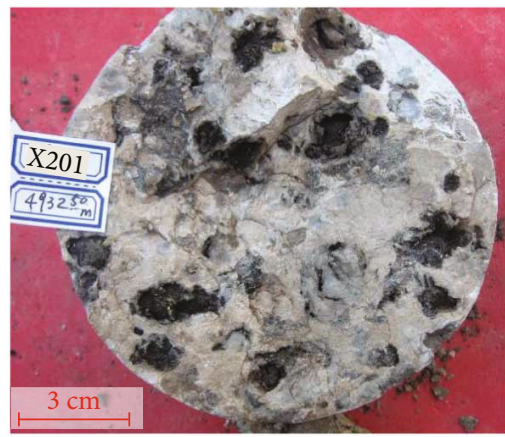

(e)

FIgure 3: (a) Photo of core taken from the third coring of Well X201. (b) 4,936.5 m, weakly fused tuff, with no development of vesicles. (c) $4,936 \mathrm{~m}$, fused tuff, with the number of vesicles increasing upwards. (d) 4,935.6 m, strongly fused tuff, with well-developed vesicles. (e) 4,932.5 $\mathrm{m}$, fused tuff, with the number of vesicles decreasing upwards.

the upper atmosphere, but most of the magma became magmatic pyroclast, vitric pyroclast, rock debris, dust, and other materials. This was in a semimolten state, mixed with some lava lumps, and solidified in the volcanic conduit during the early period. Following a subsequent explosion at the crater, rock debris rapidly overflowed down the volcano and into the nearby low-lying lake. At this time, the extremely high-temperature pyroclastic flow quickly vaporized the water into high-pressure water vapor, which was squeezed into the pyroclastic flow and became mixed with a small quantity of volatile matters; at the same time, the temperature of the pyroclastic flow decreased rapidly, the pyroclastic material solidified into rock, and the vesicles therein were preserved (Figure 4).
There are three key aspects of this formation process: the location of the crater; the influence of vaporized water on the formation of fused rocks and vesicles; and the relationship between vertical zoning, water temperature, and magma eruption speed. The text below discusses these three aspects.

(1) Location of the crater. The sedimentary environment at that time was a semideep to deep lake, but paleomorphological undulations suggest the terrain of the fractured crater was relatively high and should have been near the water surface. The volcanic ash was also deposited in areas far from the crater, indicating that the volcano erupted above the water surface, and that some volcanic ash was ejected into 


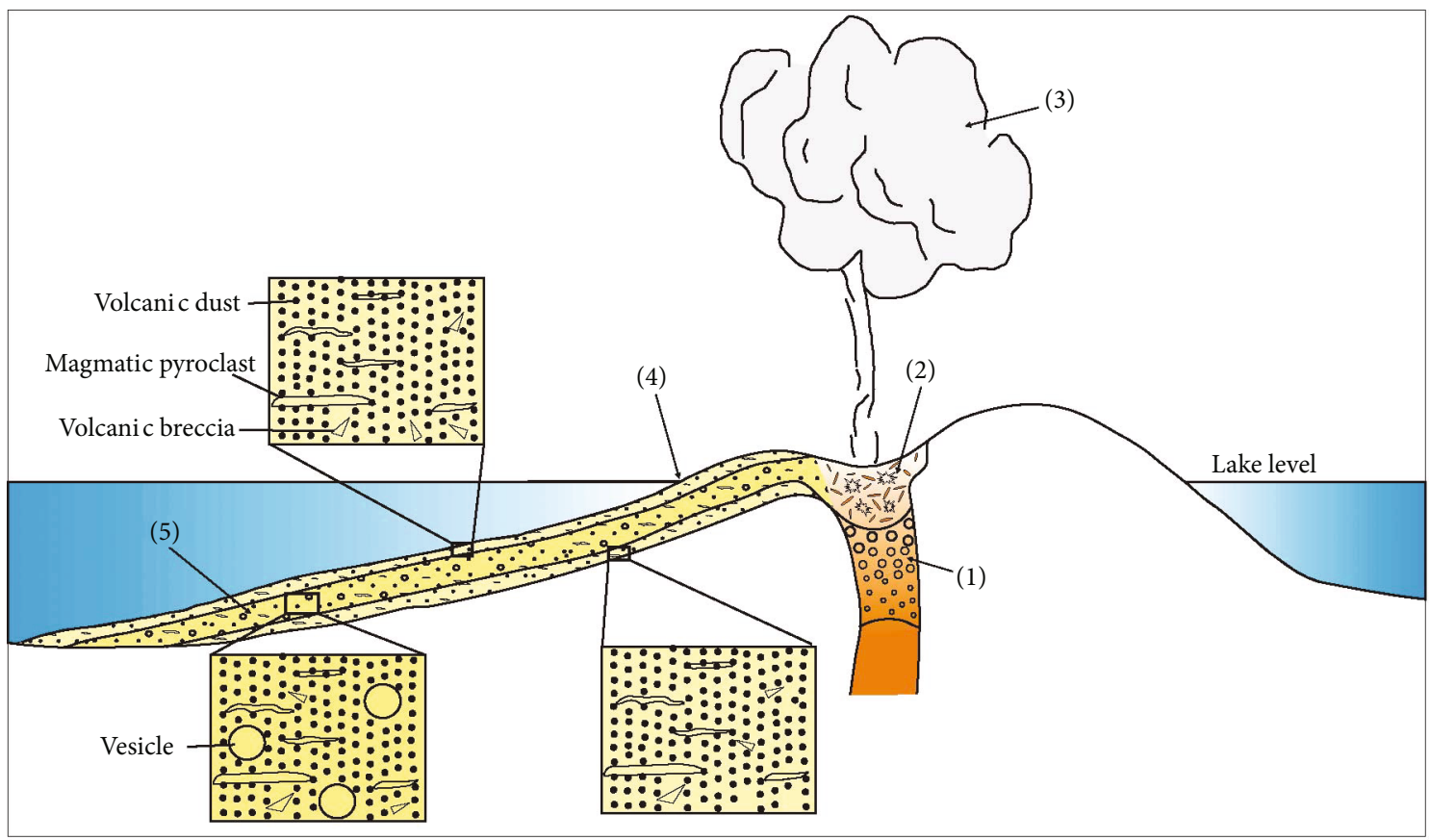

FIGURE 4: Schematic of the formation mechanism of fused breccia tuff vesicles in the Wuxia region, modified according to literature [32]. Numbers indicate the formation process of the vesicles: (1) magma rises volatile material foam, (2) explosion at the surface, (3) a small part of the volcanic dust and pyroclastic material is erupted into the upper atmosphere, (4) the hot magma flows into the lake, and (5) high-pressure water vapor is squeezed into the pyroclastic flow.

the atmosphere and was then deposited remotely together with detrital materials, forming tuffaceous sandy mudstone

(2) Influence of nearby lake water on the formation of fused rocks and vesicles. After eruption, the semimolten volcanic ash flow reached the lake near the crater, and the vaporized water was the main reason for the enrichment of the fused breccia tuff stoma. Once the volcanic material had erupted out of the crater, most volatile materials in the molten lava were degassed due to the sudden drop of pressure, and only a small proportion of the volatile materials contributed to the formation of vesicles. At that time, the terrain near the crater was relatively gentle, and this set of volcanic rocks was deposited as a layer with generally uniform thickness. The volcanic ash reaching the lake quickly vaporized the lake water, generating high pressure which not only squeezed a part of the water vapor into the volcanic ash flow but also decreased the remelting point of the volcanic ash flow; this promoted the remelting of the volcanic materials, which would form the fused breccia structure with the vesicles preserved. $\mathrm{Wu}$ et al. concluded that the melting point of volcanic rock varies under different water pressure conditions (with increasing water pressure, the melting point of volcanic rock decreases); our proposed model thus supports their viewpoint [31]

(3) Relationship between the vertical zoning, the temperature of lake water, and the quantities of eruption materials. The quantity of vaporized water was related to the temperature and scale of the semimolten volcanic ash flow. At the beginning of the eruption, the temperature of the water body was low, and the volcanic ash flowing into the lake water quickly cooled down without being fused. This generated only a little water vapor, but with the further inflow of volcanic ash, the temperature of the water body increased and reached the boiling point. Thereafter, gasification was intense and many bubbles were generated. The volcanic eruption intensity then waned later in the episode, the rate of volcanic ash flow into the water body diminished, and the pyroclastic debris was no longer fused. This is also the reason why the fused breccia tuff is divided into three vertical zones. This model clearly explains the paleogeographical environment of this set of volcanic rocks at that time and accounts for the particular external influences leading to the difference in diagenetic process between this and a conventional volcanic ash flow

5.1.2. Filling Mechanism of Vesicles. Core observations showed that vesicles developed in this set of fused breccia tuff, but with varying levels of filling. The fillings in the vesicles were mainly composed of quartz, calcite, and chlorite, which belong to clastic minerals, indicating that they were filled later. Studies have shown that the vesicle filling mechanism is closely related to the tectonic activity, and that areas with strong tectonic activity typically have filled vesicles. In the X72 well area, the Permian tectonic movement was relatively weak, faulting only penetrated the bottom boundary of the Fengcheng Formation, and the vesicles of the tuff were 
not filled; in contrast, in the X76 well area, the early Permian tectonic movement was relatively strong, faulting penetrated the top boundary of the Permian system, and the thrusting tectonic movement was more intense in the later period, making the stratigraphic dip steeper. The tectonic movements of two stages were superimposed, the strata near the fault zone were broken, and fractures developed and connected with the surface water. The surface water contained a large amount of $\mathrm{CO}_{2}$, which forms carbonic acid when dissolved and thus plays an extremely important role in the decomposition of many minerals (especially silicate and aluminosilicate minerals). At this time, $\mathrm{SiO}_{2}$ and $\mathrm{CaCO}_{3}$ were decomposed [38]. The decomposition reactions are as follows:

(1) $\mathrm{CaSiO}_{3}+\mathrm{CO}_{2}+\mathrm{nH}_{2} \mathrm{O} \longrightarrow \mathrm{CaCO}_{3}+\mathrm{SiO}_{2}+\mathrm{nH}_{2} \mathrm{O}$

(2) $4 \mathrm{KAlSi}_{3} \mathrm{O}_{8}+2 \mathrm{CO}_{2}+4 \mathrm{H}_{2} \mathrm{O}=2 \mathrm{~K}_{2} \mathrm{CO}_{3}+\mathrm{Al}_{4}\left[\mathrm{Si}_{4} \mathrm{O}_{10}\right]$ $(\mathrm{OH})_{8}+8 \mathrm{SiO}_{2}$

When the contents of $\mathrm{SiO}_{2}$ and $\mathrm{CaCO}_{3}$ in the stoma fluid reached saturation, deposition took place and the vesicles were filled. The above analysis indicates that the storage space in the fused breccia tuff was mainly provided by the primary vesicles: faults and fractures developed under strong tectonic movement in the later period, surface water (containing carbon dioxide and other substances) penetrated into the vesicles through the faults and fractures, and deposition of $\mathrm{SiO}_{2}$ and $\mathrm{CaCO}_{3}$ then filled the fractures. On this basis, the genetic model of stoma filling in volcanic rock reservoirs was established.

5.2. Quantitative Prediction of Vesicle Development and Filling. The development and filling of vesicles directly determine the quality of this set of volcanic reservoirs. Therefore, predicting the development and filling of vesicles is key to the success of oil and gas exploration in the research area. The quantitative method to predict the vesicle development and filling is as follows. Firstly, establish a geological model of the volcanic reservoir according to observations collected in the research area and then use the wave equation numerical simulation method to carry out forward modeling. Next, analyze the forward modeling results, determine how the development and filling of vesicles control the seismic sensitivity parameters, and establish a quantitative interpretation chart between them. Finally, use the $3 \mathrm{D}$ seismic data volume to extract the sensitivity attributes, quantitatively interpret the attributes, and predict the distribution of high-quality volcanic reservoirs.

5.2.1. Establishing the Geological Model. The framework of the geological model is designed according to the seismic profile. The velocity and density at the well point are calculated by logging curves. The velocity and density between wells are then obtained by interpolation. Eight wells in the research area encountered volcanic rocks; the logging response characteristics of volcanic rocks were relatively obvious, with the characteristics of high resistivity, high natural gamma, high interval transit time, and low density. These were easily identified in the logging data. Due to the complexity of volcanic reservoirs in the work area, the volcanic reservoirs were divided into three types: the first type has developed and unfilled vesicles, porosity $25 \%-15 \%$; the second type has less developed or partially filled vesicles, porosity $15 \%-5 \%$; the third type has undeveloped or completely filled vesicles, porosity less than 5\%. The first type of reservoir was taken as an example to establish the geological model: the typical well is Well X72, with an interval velocity of $4,300 \mathrm{~m} / \mathrm{s}$ and the density of $2.3 \mathrm{~g} / \mathrm{m}^{3}$. For the convenience of comparison, the geological models of Wells X72-X202$\mathrm{X} 40$ were also established (Figure 5(a)). The designed spatial extent of the model is $1,200 \mathrm{~m}$, which is consistent with the actual distance between wells, and the model depth is set to $4,300 \mathrm{~m}$; the arrangements of shot points, geophone points, and the acquisition parameters are quoted from field seismic survey data of this area. The geological models of the second and third types of reservoirs are similar to the model of the first type: the typical well of the second type of reservoir is Well X88, and the parameters used in the geological model at Well X72 include the interval velocity and density of Well $\mathrm{X} 88$, which are $4,490 \mathrm{~m} / \mathrm{s}$ and $2.45 \mathrm{~g} / \mathrm{m}^{3}$, respectively; the typical well of the third type of reservoir is Well Q8, and the parameters used in the geological model at Well X72 include the layer velocity and density of Well Q8, which are $4,590 \mathrm{~m} / \mathrm{s}$ and $2.5 \mathrm{~g} / \mathrm{m}^{3}$, respectively.

5.2.2. Forward Modeling. To establish the geological model, forward modeling of the seismic wave field was used for forward modeling of the development and filling degree of the vesicles. Forward modeling of the seismic wave field primarily includes the wave equation method and geometric ray method. The wave equation numerical simulation method essentially solves the wave equation for seismic waves. The simulated seismic wave field contains all the information on the seismic wave propagation, but the calculation speed is slower than the geometric ray method $[39,40]$. As exploration accuracy requirements have become more stringent in recent years, wave field modeling using the numerical solution of the wave equation has developed very fast, for example, based on the finite difference method [41], the finite element method, the integral method, and the $f-k$ domain method [42]. The finite difference method is the most commonly used forward modeling method, as its accuracy is continuously improving and it can model all wave field effects of seismic wave propagation in complex anisotropic media. In this study, the finite difference method was used to perform simulations based on the above three geological models. According to the migration profiles, the first model showed developed and unfilled vesicles, and its seismic reflection characteristics were high energy and strong amplitude (value 114) (Figure 5(b)). The second model showed less developed or partially filled vesicles, and its seismic reflection characteristics were medium energy and medium amplitude (value 62) (Figure 5(c)). The third model showed undeveloped or completely filled vesicles, and its seismic reflection characteristics were low energy and weak amplitude (value 53) (Figure 5(d)). It can be concluded from the above analysis that the interval velocity increased and the amplitude value decreased with the increasing filling of the vesicles. 


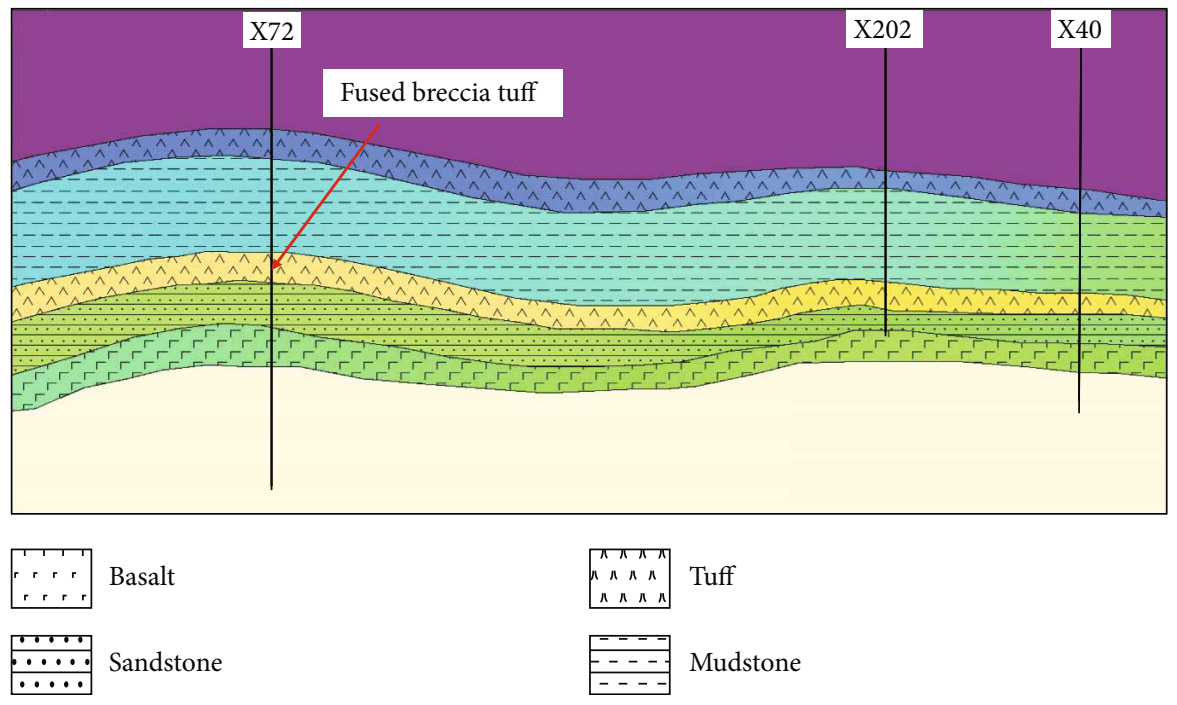

(a)

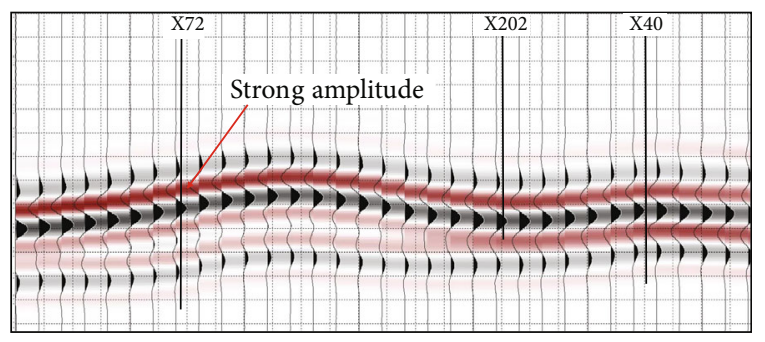

(b)

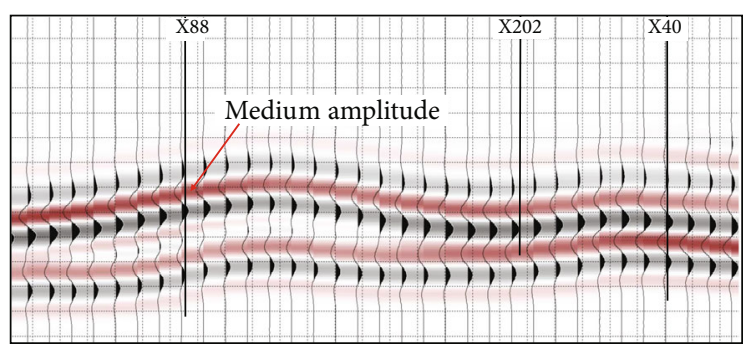

(c)

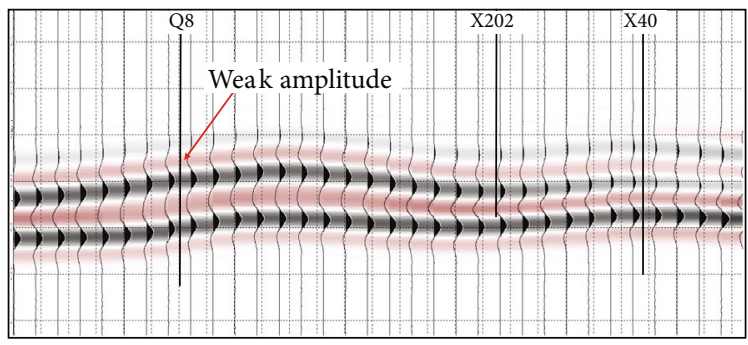

(d)

Figure 5: (a) Geological model. (b) Forward modeling migration profile of developed and unfilled vesicles. (c) Forward modeling migration profile with less developed vesicles or partially filled vesicles. (d) Forward modeling migration profile of undeveloped vesicles or filled vesicles.

5.2.3. Quantitative Prediction. The above analysis can only qualitatively show that there is a correlation between the development and filling degree of vesicles and the seismic response and cannot quantitatively analyze the quality of the reservoir. For this reason, forward modeling was carried out for 8 wells in the work area according to the above method, and the interval velocity and amplitude were obtained (Table 1). Then, the interval velocity and amplitude were cross-analyzed to establish the quantitative interpretation chart for the volcanic reservoirs (Figure 6). The interpretation chart shows that the amplitude of the reservoir with developed and unfilled vesicles is greater than 100, and the interval velocity is less than $4,380 \mathrm{~m} / \mathrm{s}$; the reservoir with less developed or partially filled vesicles has an amplitude between 60 and 100 and an interval velocity between 4,380 and $4,570 \mathrm{~m} / \mathrm{s}$; the amplitude of the reservoir with undevel- oped or completely filled vesicles is less than 60 , and the interval velocity is greater than $4,570 \mathrm{~m} / \mathrm{s}$.

On the basis of quantitative analysis, 3D seismic data were used to obtain the plane and spatial distributions of volcanic reservoirs. Firstly, the fused breccia tuff was determined as a trough reflection through fine calibration. The attributes of the maximum trough amplitude were extracted along the layer (with two-way travel time windows of $8 \mathrm{~ms}$ ) (Figure 7), and then, the attributes were reasonably explained according to the quantitative interpretation chart. It can be seen from the chart that the red area (with an amplitude value greater than 100) indicates the distribution of the reservoir with developed and unfilled vesicles, i.e., the X72 well area, which has an area of $21.4 \mathrm{~km}^{2}$, and the X89 well area (recommended well), which has an area of $60.3 \mathrm{~km}^{2}$. The green area (with an amplitude between 100 and 60) indicates 
TABLE 1: Development and filling conditions of vesicles, and the velocity and amplitude data.

\begin{tabular}{lccc}
\hline Well name & Amplitude & Velocity $(\mathrm{m} / \mathrm{s})$ & The development and filling conditions of vesicles \\
\hline X72 & 114 & 4300 & Developed and unfilled vesicles \\
X202 & 108 & 4330 & Developed and unfilled vesicles \\
X40 & 82 & 4410 & Less developed or partially filled vesicles \\
FN4 & 73 & 4470 & Less developed or partially filled vesicles \\
X76 & 62 & 4480 & Less developed or partially filled vesicles \\
X88 & 62 & 4490 & Less developed or partially filled vesicles \\
X201 & 81 & 4565 & Less developed or partially filled vesicles \\
Q8 & 53 & 4590 & Undeveloped or completely filled vesicles \\
\hline
\end{tabular}

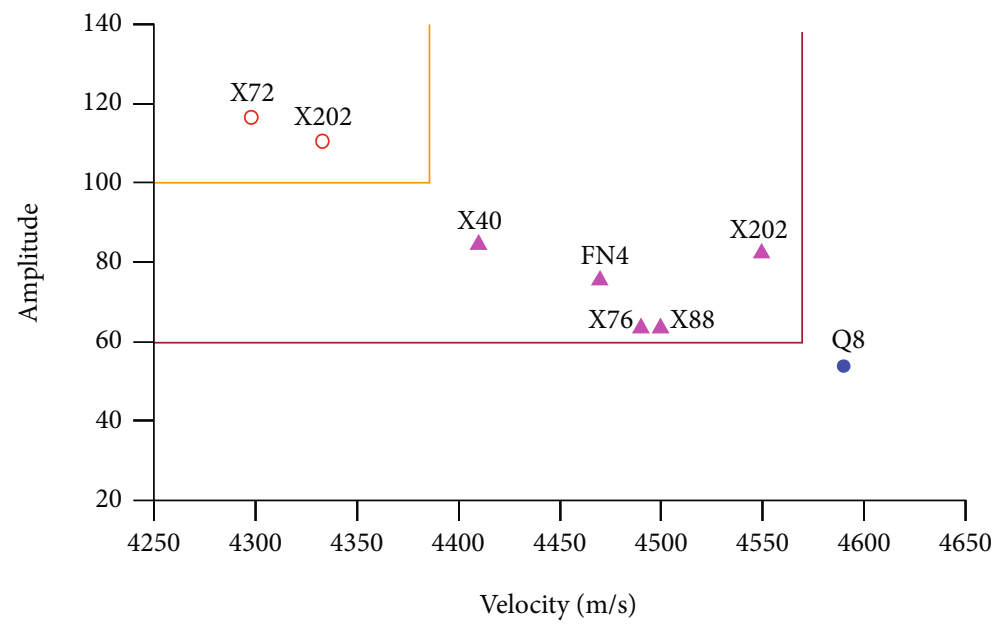

- Developed and unfilled vesicles

$\Delta$ Less developed or partially filled vesicles

- Undeveloped or completely filled vesicles

FIGURE 6: Cross plot of interval velocity and amplitude.

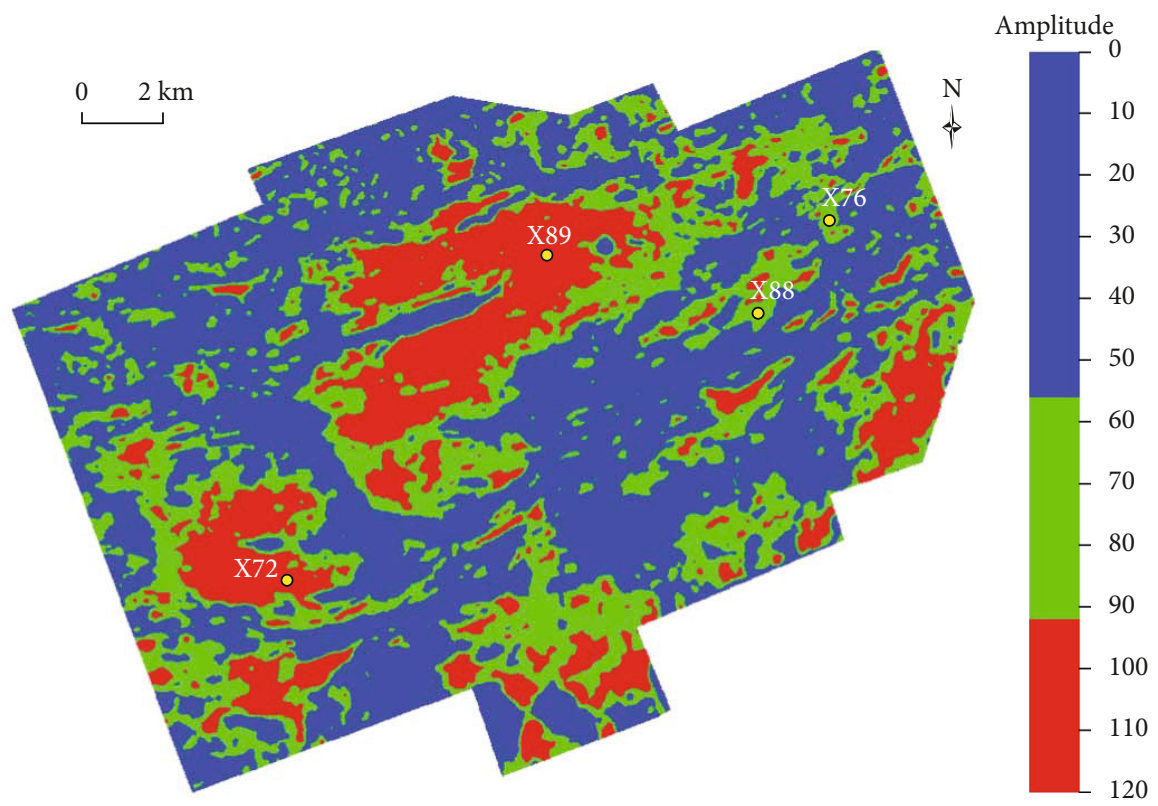

FIgURE 7: Attribute plan of maximum trough amplitude. 
the distribution of the reservoir with less developed or partially filled vesicles, i.e., the X88 well area, which has an area of $11.3 \mathrm{~km}^{2}$, and the X76 well area, which has an area of 8.6 $\mathrm{km}^{2}$; the above areas can be considered as promising exploration targets. The blue area (with an amplitude value less than 60 ) indicates the distribution of the nonreservoir rocks with undeveloped or completely filled vesicles.

The abovementioned technologies and methods were used to quantitatively predict the Permian volcanic reservoirs in Wuxia region and then to predict in detail the distribution of volcanic reservoirs with unfilled vesicles $\left(81.7 \mathrm{~km}^{2}\right)$. This yielded an estimated quantity of oil and gas resources $\left(2562 \times 10^{4} \mathrm{t}\right)$. The drilling of Well X89 encountered the fused breccia tuff in the Fengcheng Formation, where vesicles were developed but not filled, and the effective porosity is $23 \%$. The layer velocity calculated from the logging curve is $4330 \mathrm{~m} / \mathrm{s}$, which is consistent with the crossplot in Figure 6. This well yielded industrial oil and gas flow.

\section{Conclusions}

(1) The ancient crater of the Permian Fengcheng Formation in the Wuxia region was located near a former water surface. Affected by tectonic movement, in the high-temperature and high-pressure environment, the intermediate-acidic lava containing volatile materials in the deep crust rapidly rose to the earth's surface along a fault. The highly saturated volatile components in the lava foamed strongly and then exploded, due to the sharp decline of pressure and temperature. A small proportion of the volcanic dust and pyroclastic material was erupted into the upper atmosphere, but most of the magma became magmatic pyroclast, vitric pyroclast, rock debris, dust, and other materials. This was in a semimolten state mixed with some lava lumps that solidified in the volcanic conduit in an earlier period. When this material exploded from the crater, it rapidly overflowed into the nearby lake. The extremely high-temperature pyroclastic flow quickly vaporized the water into high-pressure water vapor, which was squeezed into the pyroclastic flow became mixed with a small amount of volatile materials. At the same time, the pyroclastic flow became remelted in the high-pressure environment, and the vesicles were preserved

(2) The fillings in the vesicles were mainly quartz, calcite, and chlorite, which belong to clastic minerals, indicating that they were filled in a later period. Previous research has shown that the mechanism of stoma filling is closely related to tectonic activity. The strong tectonic movement in a later period led to the development of faults and fractures, and the surface water penetrated into the tuff vesicles through the faults and fractures. Silicon dioxide and other dissolved minerals were then deposited, thus filling the primary vesicles
(3) Wave equation forward modeling, interval velocity and seismic amplitude cross-analysis, and seismic attribute extraction are key technologies for quantitative prediction of volcanic reservoirs. Wave equation forward modeling can determine the seismic response characteristics of three types of reservoirs (with developed and unfilled vesicles, less developed or partially filled vesicles, or undeveloped or completely filled vesicles). This method can establish a quantitative relationship between different reservoirs and seismic amplitudes, thus laying the foundation for reservoir prediction. Here, the prediction results are consistent with the drilling observations, thereby demonstrating that this technology is an effective way to explore such volcanic reservoirs and is worthy of widespread application in similar regions

\section{Data Availability}

All data are available on request.

\section{Conflicts of Interest}

The authors declare that they have no conflicts of interest.

\section{Acknowledgments}

This work is financially supported by the China National Science and Technology Major Projects (Grant no. 2017ZX05001-003).

\section{References}

[1] Z. S. Zhang and B. H. Wu, "Domestic and foreign research status and exploration technology of volcanic reservoir," Natural Gas Exploration and Development, vol. 16, no. 1, pp. 1-26, 1994.

[2] G. Y. Zhang, C. N. Zhou, R. K. Zhu, Y. Xuanjun, and Z. Xia, "Petroleum geology and exploration for volcanic reservoirs in the sedimentary basins of China," Engineering Science, vol. 12 , no. 5 , pp. $30-37,2010$.

[3] J. G. Pan, F. Hao, K. J. Tan et al., "Characteristic and accumulation of Paleozoic volcanic rock reservoirs in Hongche fault belt, Junggar basin," Lithologic Reservoirs, vol. 19, no. 2, pp. 53-56, 2007.

[4] J. G. Pan, Y. B. Chen, D. N. Xu et al., "Volcanic eruption pattern and distribution of Fengcheng reservoir of Permian in Wellblock Xia-72, northwestern margin of Junggar basin," Xinjiang Petroleum Geology, vol. 29, no. 5, pp. 551-552, 2008.

[5] R. L. Smith, "Ash flows," Geological Society of American Bulletin, vol. 71, no. 6, pp. 795-841, 1960.

[6] R. L. Smith, Zones and Zonal Variations in Welded Ash Flows, USGS Professional Paper, 345F, 1960.

[7] H. U. Schmincke and D. A. Swanson, "Laminar viscous flow age structures in ash-flow tuffs from Gran Canria, Canary Islands," The Journal of Geology, vol. 75, no. 6, pp. 641-664, 1967.

[8] R. S. J. Sparks and G. P. L. Walker, "The ground surge deposit: a third type of pyroclastic rock," Nature Physical Science, vol. 241, no. 107, pp. 62-64, 1973. 
[9] Y. N. Bao, "The origin of ignimbrite," Regional Geology of China, vol. 3, no. 1, pp. 99-104, 1983.

[10] R. V. . Fisher and H. U. Schmincke, Pyroclastic Rocks, Springer Verlag, New York, 1984.

[11] Q. W. Zhu, "The origin study of the welding tuffs is more deep," Geological Bulletin of Science and Technology, vol. 4, no. 3, pp. 68-71, 1985.

[12] M. J. Branney, B. P. Kokelaar, and B. J. McConnell, "The Bad Step Tuff: a lava-like rheomorphic ignimbrite in a calcalkaline piecemeal caldera, English Lake District," Bulletin of Volcanology, vol. 54, no. 3, pp. 187-199, 1992.

[13] J. Y. Xie, "The identification of the welding ignimbrites degree," Volcanology and Mineral Resources, vol. 16, no. 1, p. 51, 1995.

[14] M. H. Chen, "The discovery of welded tuffs in marine volcanic strata in Longzhou region," Guangxi Geology, vol. 8, no. 2, p. 48, 1995.

[15] C. S. Ross and R. L. Smith, Ash-Flow Tuffs: Their Origin Geologic Relations and Identification, United States Government Printing Office, Washington, 1966.

[16] P. J. Wang, C. Q. Zhen, P. Shu et al., "Classification of deep volcanic rocks in Songliao basin," Petroleum Geology and Oilfield Development in Daqing, vol. 26, no. 4, pp. 17-22, 2007.

[17] J. A. Boyce and R. Gertisser, "Variations in welding characteristics within the Plinian air-fall deposit of the Middle Pumice eruption, Santorini, Greece," Journal of Volcanology Geothermal Research, vol. 221-222, pp. 71-82, 2012.

[18] Y. Y. Cao, N. Li, and Y. Zhang, "A discussion on the welding process of pyroclastic rocks and a review of its present research state both in China and abroad," Acta Petrologica et Mineralogica, vol. 32, no. 2, pp. 239-250, 2013.

[19] Y. B. Chen, J. G. Pan, D. N. Xu et al., "Integrated geophysical prediction of volcanic reservoir in northwestern margin area of Junggar basin," Geophysical Prospecting for Petroleum, vol. 49, no. 4, pp. 364-372, 2010.

[20] J. L. Luo, H. M. Shao, and C. L. Zhang, "Research methods and exploration technologies for volcanic reservoirs," Acta Petrolei Sinica, vol. 24, no. 1, pp. 31-38, 2003.

[21] H. Z. Yan, X. M. Liu, W. T. Cai, and D. Q. Xiao, "Seismic technology comprehensive application for igneous reservoir," Oil Geophysical Prospecting, vol. 34, pp. 89-95, 1999.

[22] D. N. Xu, C. L. Jiang, J. G. Pan et al., “Application of Epos 3.0 seismic interpretation system to volcanic reservoir exploration in Chepaizi area of Junggar Basin," Lithologic Reservoirs, vol. 21, no. 1, pp. 112-114, 2009.

[23] Y. X. Wang, D. K. Han, and W. L. Liu, "The application of coherence technology in the volcanic reservoir prediction," Geophysical Prospecting for Petroleum, vol. 45, no. 2, pp. 192-196, 2006.

[24] K. J. Tan, F. Zhang, J. G. Pan, D. N. Xu, L. J. Huang, and Y. B. Chen, "Quantitative prediction technology of high quality volcanic reservoir and its application," Natural Gas Geoscience, vol. 23, no. 1, pp. 175-180, 2012.

[25] Y. M. Li, Y. L. Li, W. L. Zhao, and G. Y. Cao, "Research on the quantitative prediction method of deep volcanic reservoir," Oil Geophysical Prospecting, vol. 37, no. 2, pp. 175-179, 2001.

[26] Y. X. Wu, P. J. Wang, and L. Yan, "Quantitative modelling and application of volcanic facies of Lower Cretaceous Yingcheng formation of the Songliao basin," Acta Petrologica Sinica, vol. 26, no. 1, pp. 73-81, 2010.
[27] J. Z. Zhang, J. Cao, Y. Wang et al., "Geochemistry and genesis of oil and gas seeps in the Junggar Basin, NW China: implications for hybrid petroleum systems," Geofluids, vol. 2019, Article ID 9732674, 26 pages, 2019.

[28] J. W. Feng, J. S. Dai, J. H. Yan, L. L. Huang, and J. Wang, "Sedimentary response to Permian structural movements in Wuxia foreland thrust belt of Junggar basin," Acta Sedimentologica Sinica, vol. 27, no. 3, pp. 494-502, 2009.

[29] G. H. Zhu, Origin of Pyroclastic Rock in the Well Xia-72 Area, Research Institute of Xinjiang Oilfield, Karamay, 2009.

[30] Y. X. Xiao, J. Li, and X. Y. Liu, "Genetic analysis of deep seated vesicular rhyolitic igneous pyroclastic rocks-a case study of the volcanic reservoir in Wellblock Xia-72 at the northwestern margin of Junggar basin," Journal of Oil and Gas Technology, vol. 30, no. 5, pp. 22-26, 2008.

[31] Y. Q. Wu, Q. S. Chang, Y. Q. Jiang, Z. J. Sun, G. J. Wang, and H. X. Yang, "Genetic characteristics of vesicular volcanic clastic reservoir of Fengcheng Formation in Wellblock Xia-72 and its significance for hydrocarbon exploration," Xinjiang Petroleum Geology, vol. 27, no. 2, pp. 166-168, 2006.

[32] S. F. Zhu, X. M. Zhu, J. S. Liu, Y. Yao, B. Z. Xian, and H. Niu, "Genesis and hydrocarbon significance of vesicular ignimbrite: a case study from Fengcheng Formation, Wu-xia area, Junggar basin, NW China," Petroleum Exploration and Development, vol. 39, no. 2, pp. 162-171, 2012.

[33] J. Q. Wang, W. Z. Liu, S. L. Yang, P. J. Wang, and Z. J. Xu, "Characteristics and genesis of lithophysa in rhyolite of Yingcheng Formation, Songliao basin," Journal of Jilin University: Earth Science Edition, vol. 37, no. 6, pp. 1266-1271, 2007.

[34] M. H. Chen, "Study of rhyolite welded breccia tuff of margin facies in Longzhou region," Guangxi Geology, vol. 10, no. 1, pp. 1-6, 1997.

[35] X. D. You, "Discussion on sedimentary facies of Fengcheng Formation in northwest margin of Junggar Basin," Xinjiang Petroleum Geology, vol. 7, no. 1, pp. 46-52, 1986.

[36] J. H. Yan, Y. B. Cui, S. Y. Chen, and Z. Lu, "Sedimantary features and favorable reservoirs of Permian in Wu-xia area of Junggar Basin," Xinjiang Petroleum Geology, vol. 30, no. 3, pp. 304-306, 2009.

[37] Y. X. He, B. Z. Xian, H. P. Niu, X. L. Zhang, and J. N. Shen, "Discrimination of volcanic eruption environment using oxidation index: a case study of Lower Permian volcanic rocks in northwestern margin of Junggar Basin," Geological Journal of China Universities, vol. 23, no. 4, pp. 737749, 2017.

[38] M. Xiao, X. J. Yuan, D. W. Cheng et al., "Feldspar dissolution and its influence on reservoirs: a case study of the Lower Triassic Baikouquan Formation in the northwest margin of the Junggar Basin, China," Geofluids, vol. 2018, Article ID 6536419, 19 pages, 2018.

[39] Y. G. Zhang, "On numerical simulations of seismic wavefield," Geophysical Prospecting for Petroleum, vol. 42, no. 2, pp. 143148, 2003.

[40] Ö. Yilmaz, Seismic Data Analysis, X. D. Huang and M. D. Yuan, Eds., Petroleum Industry Press, Interpret Beijing, 1994.

[41] R. M. Alford, K. R. Kelly, and D. M. Boore, "Accuracy of finite difference modeling of the acoustic wave equation," Geophysics, vol. 39, no. 6, pp. 834-842, 1974.

[42] X. B. Xiong and Z. H. He, "Phase-shift plus finite-difference wave equation forward modeling," Geophysical Prospecting for Petroleum, vol. 37, no. 3, pp. 22-28, 1998. 